\title{
Efectos de la Gran Guerra en la prensa valenciana: un cambio de ciclo
}

\author{
Antonio Laguna Platero \\ Universidad de Castilla-La Mancha \\ antonio.laguna@uclm.es
}

Recibido: 15 de junio de 2013

Aceptado: 16 de julio de 2013

\section{Resumen}

La Gran Guerra que se libró en el continente europeo entre 1914 y 1918 fue el primer acontecimiento general que concitó el interés y la curiosidad de buena parte de la población mundial. Un drama que generó diversos efectos en el mundo de la prensa, desde un incremento en la demanda informativa, pasando por una consolidación definitiva del fotoperiodismo hasta una importante carestía del precio del papel. Pero también generó una crisis social de gran intensidad entre los trabajadores del mundo de la prensa y un cambio de ciclo en la tendencia modernizadora iniciada décadas atrás.

Palabras clave: periódicos; información; guerra; papel; crisis.

\section{Effects of the Great War in the of Valencia Press: a change of cycle}

\begin{abstract}
The Great War was fought in Europe between 1914 and 1918 was the first general event aroused the interest and curiosity of many of the world's population. A drama that generated different effects on the world of media, from an increase in the demand for information, to a final consolidation of photojournalism to a major princein the price of paper. But it also generated a very intense social crisis between workers in the world's press and a change in the trend cycle started decades ago.
\end{abstract}

Keywords: newspapers; information; war; paper; crisis.

\section{Referencia normalizada}

Laguna Platero, A. (2013) Efectos de la Gran Guerra en la prensa valenciana: un cambio de ciclo. Historia y Comunicación Social. Vol. 18, págs. 275-291.

Sumario: 1. Introducción. 2. El Impacto periodístico de la Guerra. 3. Aliadófilos contra germanófilos, la oportunidad de una polémica. 4. Un papel crítico para la prensa. 5. Conclusiones tras la Guerra: volver a ser competitivos. 6. Bibliografía.

\section{Introducción}

Nunca antes se había desatado un acontecimiento militar de esas dimensiones. Nunca hasta entonces se había visto implicado tan gran volumen de personas en una misma conflagración, unos en el campo cruel de la batalla defendiendo la causa de 
la patria, otros en la retaguardia observando perplejos la evolución de la tecnología militar y su capacidad destructora. Todo era nuevo, pura expectación, intenso drama en proporciones coherentes con las nuevas sociedades de masas que habitan los países en conflicto. Fue el comienzo de una nueva era, de un siglo corto en palabras de Hobsbawm, que provocó trascendentales impactos en las vidas de las personas, así como en sus medios de comunicación y en las estrategias persuasivas desarrolladas hasta el momento.

El estudio de los efectos que la coyuntura bélica internacional tuvo sobre nuestro país ha sido objeto de diversos trabajos, especialmente desde la perspectiva económica. José Luis García Delgado y Juan Carlos Jiménez (2001:51) han señalado la "consolidación del nacionalismo económico", describiendo las fases sucesivas que se vivieron de desconcierto inicial, aprovechamiento posterior y crisis final con un impacto que facilitaría la llegada de la dictadura de Primo. También ha merecido especial atención el tránsito que se opera en esta coyuntura entre las políticas de las élites y las de masas. Italia primero y España después son los ejemplos que permiten al profesor Edward Acton (2001: 197) aseverar que la guerra aceleró esta transición en buena parte de Europa. En el caso español no hay duda que el impacto bélico constituyó el último episodio de un sistema establecido en 1876, muy tocado por los "tumores" de la "oligarquía y el caciquismo" señalados por Costa unos años antes. Un fin de ciclo acelerado a partir de 1917 por la creciente respuesta obrera y que tanto asustó a una burguesía que no quitaba ojo a los sucesos de la vieja Rusia. La opción militar de 1923, además de salvar la cara a Alfonso XIII ante sus posibles implicaciones en el desastre de Annual, constituirá la nueva apuesta de la burguesía española por establecer una nueva fórmula de dominio político y crecimiento económico.

En el ámbito de la producción periodística, a pesar del progreso que experimenta el documental cinematográfico (Paz y Montero, 1999: 52-63), la prensa sigue siendo el medio básico fundamental de comunicación entre las personas, ya fuese de forma directa con la compra y lectura del ejemplar, ya fuese por otra vía indirecta de participación en sus contenidos. Además, con la novedad significativa que implica la progresiva incorporación del mundo obrero al consumo de medios y a la participación política. Tanto Gómez Mompart como Espinet (1989), en sus respectivos trabajos acerca de la irrupción de la prensa de masas en España, destacaban esta clave cualitativa, más allá de las mediciones de tiradas y de cabeceras, como indicador de una prensa de masas.

La prensa, por tanto, llega a la segunda década del siglo XX con un debate en ciernes de insospechadas consecuencias acerca de la incesante mercantilización del proceso informativo. Nunca como hasta ese momento se habían publicado tantas reflexiones acerca de qué modelo es el más periodístico, si el de partido o el de empresa. Nunca como hasta ese momento, la estructura empresarial de la prensa española había alcanzado tal nivel de concentración, de modernización y de posibilidades económicas. Y es que la rentabilidad del periódico acelera la conversión del modelo tradicional de hacer periódicos en empresa que hace de la competitividad uno de sus fines prioritarios. Para ello renovará utillaje, incrementará plantillas, 
especialmente relacionada con los objetivos comerciales y publicitarios, ampliará páginas y secciones, incorporará nuevos géneros como el fotoperiodismo y apelará al sistema de promociones para fidelizar clientelas. Sin embargo, la tendencia se verá abruptamente parada con motivo de la I Guerra Mundial. El mercado valenciano, el tercero en importancia en el mapa español, se convierte en el mejor ejemplo de las consecuencias que para el mundo de la producción periodística tuvo la Gran Guerra.

\section{El impacto periodístico de la guerra}

En términos generales, el impacto de la contienda en el mundo de la prensa pasará por las mismas fases que lo señalado para la economía (Sáiz y Seoane, 1996: 212 y ss.). Si en los inicios del conflicto, todo apuntaba hacia una aceleración de las ventas por el interés que despierta en el público, pasado esta primera fase todo se volverá en contra. Primero la censura que imponen las autoridades militares o civiles. Después el aumento de los gastos telegráficos y de agencia que suministran la información del teatro de operaciones, unido al importante aumento de los precios del papel. Finalmente, un retraimiento del consumo y una bajada de la actividad industrial y mercantil que afecta negativamente a la inversión publicitaria. La estadística de la que disponemos nos permite una somera aproximación cuantitativa. En primer lugar, tres calas cronológicas en la medición total de cabeceras ofertadas, donde se confirma que el crecimiento operado en la primera década del siglo -en torno al $47 \%$ y un avance de más 633 cabeceras- se ralentiza en la segunda con un avance sólo de 121 cabeceras nuevas y un crecimiento del $6 \%$.

Cuadro nº 1: Evolución del número de cabeceras

\begin{tabular}{|l|c|c|c|}
\hline PROVINCIAS & $\mathbf{N}^{\mathbf{0}}$ Periódicos 1900 & 1913 & 1920 \\
\hline MADRID & 328 & 459 & 522 \\
\hline BARCELONA & 158 & 323 & 431 \\
\hline VALENCIA & 78 & 88 & 40 \\
\hline SEVILLA & 36 & 52 & 44 \\
\hline MALAGA & 18 & 40 & 33 \\
\hline TOTAL ESPAÑA & 1347 & 1980 & 2101 \\
\hline
\end{tabular}

Fondo documental del Instituto Nacional de Estadística

El profesor Guereña (1982:114) nos permite completar esta medición con el desglose de la oferta por el criterio de la periodicidad, confirmándose de nuevo el retroceso observado. Si en 1913 se contabilizaban en toda España 312 diarios, en 1920 la cifra había descendido a 290. Por su parte, P. Aubert (1986: 372) apunta una reducción de los semanarios del 8\% entre 1913 y 1920, y un 14\% de los diarios. En síntesis, la primera consecuencia que se desprende del impacto de la guerra será una crisis general, un cambio de ciclo que abocará a una parte de los medios a graves problemas económicos cuando no a la desaparición. 
La prensa valenciana, campo de especial atención en nuestra investigación, nos ofrece reiterados ejemplos en este sentido. Si medimos en primer lugar la oferta de periódicos en el mercado valenciano, el resultado que obtenemos informa del retroceso experimentado:

Cuadro n 2: Evolución oferta prensa valenciana

\begin{tabular}{|c|c|c|}
\hline & Diarios & No diarios \\
\hline $\mathbf{1 9 1 4}$ & 10 & 112 \\
\hline $\mathbf{1 9 1 5}$ & 8 & 110 \\
\hline $\mathbf{1 9 1 6}$ & 7 & 123 \\
\hline $\mathbf{1 9 1 7}$ & 6 & 100 \\
\hline $\mathbf{1 9 1 8}$ & 7 & 100 \\
\hline $\mathbf{1 9 1 9}$ & 8 & 92 \\
\hline $\mathbf{1 9 2 0}$ & 8 & 91 \\
\hline
\end{tabular}

Fuente: Almanaques de Las Provincias

Junto a la contracción de la oferta, otro efecto no menos importante es la desaceleración de los procesos de modernización empresarial y productiva que venían caracterizando a la prensa española en general desde principios de siglo. La Revista Política y Parlamentaria, dirigida por Gabriel España, publicaba un número especial el 15 de septiembre de 1900 donde se hacía eco del importante momento que experimentaba la prensa diaria madrileña. Seis años después nacía el primer gran trust periodístico del país, con una plantilla de más de 1000 trabajadores y la unión de 9 diarios. La Sociedad Editorial que se crea supone una importante novedad respecto de las experiencias empresariales anteriores, especialmente las protagonizadas por los Godó en Barcelona con La Vanguardia o Luca de Tena en Madrid con $A B C$. Se trata de establecer un modelo de agrupación que permita una doble estrategia ante el mercado: por un lado, aplicar una economía de escala que abarate costes de producción, en especial el del papel; y por otro, crear un bloque con mayor capacidad de presión para negociar contratos de explotación, así como una mayor capacidad de influencia ante la opinión pública y las instancias políticas. En síntesis, un proyecto concebido para ganar dinero e influencia. Sin embargo, el futuro de esta primera gran empresa periodística estuvo marcado por la coyuntura depresiva que significó la I Guerra Mundial. De hecho, el proyecto de Sociedad Editorial que nace en 1906 se resquebraja en 1916 con la salida de El Imparcial, se agudiza en 1918 por la crisis del papel y en 1919 por la huelga de tipógrafos y periodistas, reconvirtiéndose a partir de 1922 como "Sociedad Editorial Universal" y con capital catalán (Desvois, 1977: 21 y ss.; Seoane y Saíz, 1996: 75 y ss.; Cabrera, 1994: 48 y ss.; Sánchez Yllán, 1999: 189 y ss.).

El ejemplo que acabamos de ver tiene su correlato en el caso valenciano. El proceso de renovación tecnológica del diario líder del mercado periodístico de Valencia, el periódico republicano El Mercantil Valenciano, le había llevado a ser el más moderno en 1909, con la incorporación de la rotativa más potente del mercado, capaz de imprimir 15.000 ejemplares por hora, cortados y plegados. El 3 de mayo de 1915 
anunciaba la adquisición de otra, con capacidad ahora para 24.000 ejemplares la hora y todas las características para satisfacer... "la ansiedad del lector que quiere tenerlo en su poder con información completa a primera hora de la mañana" (Rius y Laguna, 1992: 95). Pero sobre todo, lo más importante de la nueva máquina era la calidad con la que imprimía los fotograbados. El resultado será un ejemplar, con una dimensión regular entre 6 y 8 páginas, donde destacará la abundancia de imágenes. La reforma irá acompañada de una subida en los precios de la publicidad. Si antes el anuncio en primera costaba una peseta la línea, ahora pasa a 2; en la segunda, de 0'50 pasa a 1 peseta; y en las restantes, de 0'10 pasa a 0’20. Los que no varían son los precios de suscripción: 1'50 pesetas por un mes para la capital y 4'50 el trimestre. En resumen, en apenas seis años la empresa de El Mercantil realizará dos grandes cambios de máquinas rotativas. Sin embargo, el siguiente no se producirá hasta 1929. Es decir, la guerra y sus efectos retrasaron la siguiente reforma 14 años.

Lo mismo podríamos decir del otro diario más destacado en el mercado, el Diario de Valencia. Inmerso en una política expansiva desde su nacimiento en 1911, iniciaba el otoño de 1914 con las primeras dudas acerca de qué hacer. Si el Diario de Valencia "no busca el lucro sino la propaganda de sus ideas" ya que no se considera un negocio, sino "una empresa católico-política", entonces qué hacer ante el aumento de los gastos. La primera alternativa, a fines de septiembre de 1914, será anunciar a sus lectores la edición de ejemplares únicamente de 4 páginas, excepto los jueves y domingos que los harían de 6. De momento no habría más. El apoyo del partido Legitimista (carlista) en particular, y de la Iglesia en general, debía suplir el déficit que se fuese generando. Pero no sólo se reducía la calidad de la oferta, también las técnicas de promoción que había iniciado. En abril de 1915 se ponía en marcha una nueva campaña de promoción del diario, ofertando el sorteo de un segundo chalet a celebrar el 25 de julio de 1916. Pero la gravedad de la crisis económica no hará posible el sorteo hasta marzo de 1918, con la pérdida de crédito consiguiente.

Característicamente, la guerra obliga a toda la prensa diaria a cambiar su planteamiento informativo y hasta tipográfico. Todo queda supeditado al acontecimiento bélico, al interés que despierta, a las pasiones que enciende. Consecuentemente, la información internacional se convierte en la gran protagonista, lo que tendrá efectos en el diseño y maquetación. La tercera página se remodela exclusivamente para seguir el curso de la guerra.

Todos los diarios salían a la calle sobre las 6 de la mañana, incluyendo en su sección "Por telégrafo y teléfono", las últimas noticias recibidas. Todos, por tanto, habían entrado en una dura competencia por conseguir más y mejor información. Pero los tiempos no estaban para sufragar nuevas agencias, corresponsales o conciertos especiales. La media mensual de gastos reconocidos por los principales diarios superaban las 1.000 pesetas al mes en "telegramas y telefonemas"1. Por este motivo, los robos de telegramas o la edición de noticias plagiadas de otros diarios nacionales o internacionales, pasó a ser tema de enfrentamiento entre los diarios valencianos. El ejemplo más interesante lo protagoniza El Mercantil y Las Provincias. Este último había contratado en exclusiva, a principios de 1915, el servicio radiotelegráfico de la 
Compañía Nacional de Telegrafía sin Hilos, por lo que no entendía que El Mercantil publicase los mismos telegramas que él. Para averiguarlo decidió poner un anzuelo: un telegrama falso sobre un atentado al exprimer ministro francés. El Mercantil picó y lo publicó como telegrama propio lo que generó la crítica y la chanza de la competencia.

La competencia informativa tendrá un tercer invitado no deseado, la censura (Aubert, 2007). Las quejas acerca de las intervenciones oficiales en teléfonos y telégrafos para censurar o retrasar el conocimiento de noticias estarán a la orden del día. De igual forma, el control de la información relacionada con la efervescente situación social irá in crescendo. Hasta tal punto que, en abril de 1917, el presidente de la Asociación de la Prensa de Madrid, Miguel Moya, en nombre de toda la prensa solicitaba al jefe del Gobierno la supresión de la censura. El 8 de abril, el propio Moya leía, ante la expectación de todos los congregados en la Asociación de la Prensa de Madrid, la nota-contestación del Gobierno que rechazaba abiertamente cualquier relajo del sistema censor. ${ }^{2}$ Es más, a medida que la conflictividad social vaya creciendo, las acciones represoras se multiplicarán. A partir del 27 de junio de 1917, ante las amenazas de huelga y tras la convocatoria por los parlamentarios catalanes de la Asamblea, el Gobierno acordaba suspender las garantías constitucionales y establecer una férrea censura sobre la prensa. Pero ahora con una novedad añadida: si un artículo era tachado, en su lugar había que poner otro ya que quedaban prohibidos los blancos ${ }^{3}$. Precisamente, por un supuesto blanco en el número del 5 de julio, el Gobernador le imponía a El Pueblo la multa de 500 ptas. La censura adquiría una doble vertiente: junto a la norma dispositiva que la regulaba y el brazo judicial que la aplicaba, estaba la dificultad de hacer frente a los gastos de las multas, un sobreesfuerzo que, unido al que exige la cuestión del papel, podía poner en serio peligro la vida de cualquier diario. Por otro lado, resulta que la visita del fiscal con la correspondiente imposición de alguna multa, pasará a ser habitual a partir de julio de $1917^{4}$.

Finalmente, la I Guerra Mundial fue la guerra de la imagen, el conflicto a partir del cual la fotografía se iba a convertir en una exigencia y el fotoperiodismo en un novedoso género. También de las crónicas firmadas por reputados hombres de letras, a mitad de camino entre la descripción y el compromiso. Será el caso de Blasco Ibáñez, cuyas crónicas, publicadas en formas de fascículo, serán la base posterior de una de sus novelas más célebres, "Los cuatro jinetes del Apocalipsis".

A partir de 1914, donde la tecnología del progreso se hace masivamente destructora, ya no cabía el artículo describiendo los resultados de la batalla. Era preciso y así lo demandaba el público, verlo con sus ojos. Sin embargo, la presencia de fotografías no fue igual en todo el desarrollo bélico. La falta de espacio, pero también la mala calidad del papel que se empieza a utilizar a partir del verano de 1916, devolvieron al periódico su fisonomía anterior, esto es, texto por todas partes. Hasta la publicidad se vería afectada por estas limitaciones, haciéndose frecuente una cuarta plana donde el anuncio, por primera vez, se veía obligado a compartir espacio con la información. 
En resumen, la guerra fue un tiempo de oportunidades y de efectos. Fue el primer gran reto de cubrir un acontecimiento de dimensiones masivas, concretando la importancia que tenía obtener la imagen directa del suceso y despertando un enorme interés colectivo. Pero también significó un gran reto de supervivencia económica para las empresas periodísticas, que vieron como los costos de producción se multiplicaron en muy poco tiempo y los ingresos por publicidad se hundían como consecuencia del retraimiento de la actividad. También es cierto que la guerra abrió otra vía -muy poco documentada- para obtener ingresos. Se trata de las ayudas que los países en litigio ofrecieron a los diarios para que defendiesen una u otra postura dentro del gran debate nacional que se desató.

\section{Aliadófilos contra germanófilos, la oportunidad de una polémica}

La mayor parte de los diarios, en función de su línea editorial, se posicionaron a favor de uno u otro bloque. Los diarios republicanos y progresistas fueron aliadófilos y los carlistas y conservadores germanófilos. Para los primeros, Francia representaba la cuna de la revolución, el paraíso llamado república, lo que indudablemente les llevaba a ponerse de su parte. Para los segundos, esta defensa aliadófila, más allá de ideales, era consecuencia de haberse "vendido a los comités librepensadores, judíos y masones de París", por lo que no dudaba en calificarlos de periódicos que "explotan la mentira y la calumnia, asalariados del error, esclavos de la villanía, adoradores del dios Éxito, odaliscas de los que tienen dinero y les pagan sus servicios" ${ }^{5}$.

La situación iría a peor conforme avance la guerra, sobre todo a partir del momento en que Alemania convierta en objetivo militar el comercio mediterráneo, tan vital para economías exportadoras como la valenciana. De esta forma, tanto el suministro de alimentos a los países aliados, como la importación de materias primas para la fabricación, entre otros productos, del papel, quedaban definitivamente interrumpidos. Cualquier barco que intentase romperlo, corría el riesgo de destrucción por una armada que, para la prensa republicana, sólo merecía el nombre de pirata. Desde ese instante, la actitud antigermana de diarios republicanos como El Pueblo y El Mercantil se tornó más pronunciada. El 2 de febrero de 1917, bajo el artículo "La barbarie alemana arruina nuestra producción", El Pueblo denunciaba que los barcos de la Transmediterránea con destino a Francia y Gran Bretaña no pudiesen navegar libremente. Al día siguiente se hacía eco de la nota diplomática que el Gobierno alemán había hecho llegar al español advirtiéndole de que el mar era también escenario de guerra. Las consideraciones desembocan, por tanto, en una sola conclusión: la necesidad de contestar mediante la intervención. En contra escribía "kaiser-hito" en el Diario de Valencia, alter ego provincial del germanófilo diario de Ángel Herrera, El Debate, argumentando la necesidad del apoyo a Alemania. En suma, republicanos en el lado aliado, frente a católicos y conservadores en el lado alemán en un juego de identificaciones tanto ideológicas como simbólicas. 
Estos posicionamientos no sólo respondían a cuestiones ideológicas. En algunos casos tenían detrás el dinero de alguno de los países contendientes, tanto por lo que aportaban como por lo que dejaban de aportar. En términos generales, son conocidas las quejas de los directores de La Correspondencia de España y de $A B C$ por la pérdida de la publicidad de empresas francesas y alemanas, respectivamente, por sus posicionamientos en uno u otro bando (Seoane y Sáiz, 1996: 212n). También la polémica entre Luis Araquistáin y Luca de Tena a propósito del artículo publicado por el primero en el Daily News londinense el 12 de enero de 1916 acusando al propietario de $A B C$ de estar vendido a la propaganda alemana y de negarle ver sus cuentas con el Banco Alemán Trasatlántico ${ }^{6}$. Enrique Montero (1983: 245) nos descubriría la estrategia propagandística aliada del semanario que acoge la firma de Araquistain. Por su parte, el Diario de Barcelona aprovechará los flecos de este debate para denunciar a El Día Gráfico y La Tribuna de ser víctimas de la "corrupción alemana"7. Finalmente el trabajo detallado de P. Aubert (1986) nos proporciona una interesante relación de beneficiarios de esa polémica, desde los obispos hasta los periodistas que no veían mejor forma de completar sus exiguos salarios.

En la prensa valenciana, los dos casos más sonados fueron los del diario católico, La Voz de Valencia, y el nuevo Radical de Rodrigo Soriano. El primero ya daba los primeros síntomas de crisis en los inicios de 1916, cuando acusa a los católicos adinerados de haberlo abandonado a una suerte cada vez más negra. A parecer no llegaba a los 5.000 suscriptores, ya que este diario era el único que no aceptaba la venta directa. El director y propietario, Juan Pérez Lucia, "tras varios sacrificios", no tendrá más remedio que venderlo al catedrático Fernando Ros, conocido editor del semanario católico la España Cristiana y que, según el Diario de Valencia, tenía la intención de convertirlo en liberal-maurista. Sin embargo, no fue así. El 2 de agosto de 1917, Fernando Ros afirmaba haber vendido $L a V o z$ a la embajada alemana de Valencia por 11.500 pesetas, cantidad justipreciada por un ingeniero de dicha embajada ${ }^{8}$. Una información que el cónsul alemán en Valencia negará públicamente (Martínez Gallego, 1994: 105).

La otra acusación de estar vendido a la propaganda alemana fue lanzada contra Rodrigo Soriano el último día del año 17 por El Pueblo. Según el diario de Azzati, "Todo el mundo sabe que Rodrigo Soriano está vendido a los bárbaros; que España Nueva cobra 20.000 pesetas mensuales de Alemania; que 15.000 van derechas a Soriano, el cual se ha construido una magnífica mansión en la calle de Alfonso XII... Pero lo que ignorábamos era que muy en breve volverá a publicarse El Radical, de Valencia, a todo lujo, con rotativa propia, para hacerle la guerra a EL PUEBLO y para ayudar a Soriano en sus ridículas pretensiones de volver a ser diputado por la noble, liberal capital levantina". No sabemos si, en efecto, existió alguna vinculación con los agentes alemanes o la acusación no es más que una muestra más de la vieja guerra que mantenían los republicanos blasquistas de El Pueblo y los sorianistas de El Radical (Laguna, 1999). Sin embargo, lo que sí conocemos es que el 20 de enero aparecía de nuevo diario con un artículo de salutación de Soriano, titulado 'Hoy como siempre". En realidad, El Radical vuelve a la vida, sencillamente, para apoyar 
la campaña electoral de Soriano que, una vez más, concurre por Valencia. En esta campaña, sin embargo, Soriano se jugó algo más que un acta electoral: en la noche del día 16, al cruzar el coche donde iba Soriano la calle de Serranos, frente a la Iglesia de San Bartolomé, un individuo se abalanzaba sobre él y le descerrajaba dos disparos a bocajarro que impactaban en su cara y cuello. La rápida intervención quirúrgica a la que fue sometido le salvaría la vida. Además de herido, Soriano salió derrotado en las elecciones y su periódico sin ningún futuro. Y es que, en los tiempos que corrían, poner en marcha una publicación no dejaba de ser una aventura tan difícil como arriesgada.

\section{Un papel crítico para la prensa}

La guerra no sólo provocó la subida del precio de los alimentos para las personas, especialmente el pan, también provocó la subida del alimento para el periódico. Las dificultades extremas de importar desde los países del Norte la pasta con la que las fábricas españolas elaboraban el papel, fue el origen de la peor crisis de suministro con la que se van a enfrentar los periódicos españoles desde su existencia. Además, a diferencia del pasado, la producción de buena parte de las fábricas españolas se encuentra bajo una misma dirección, la de Papelera Española que preside N. M. Urgoiti. Toda la prensa diaria valenciana se nutría de esta empresa. Esta situación de monopolio le iba permitir a la Papelera variar el precio del papel en cuantas ocasiones estimó oportuno, provocando serias dificultades para la subsistencia de las empresas periodísticas mientras su cuenta de resultados progresaba (Cabrera, 1994: 88). Urgoiti, sin embrago, tenía una visión muy distinta de las causas de la crisis. En una conferencia pronunciada el 7 de diciembre de 1915 en el Ateneo madrileño, afirmará que la crisis de la prensa no estaba tanto en la crecida del precio del papel cuanto en su mala calidad y pésima organización empresarial. Es decir, para el propietario de Papelera, el problema era el peso que todavía tenía en el mercado el viejo modelo de diario partido.

Urgoiti no tenía razón en su diagnóstico. En el caso valenciano, si consideramos los diarios consolidados, tan sólo dos de ellos dependen de una organización política: El Pueblo y Diario de Valencia. Por el contrario, aunque con una línea política más o menos definida e incluso con apoyo especíico a determinados candidatos, los diarios que tenía una estructura desligada de los designios del partido son El Mercantil Valenciano, La Correspondencia de Valencia, La Voz de Valencia y Las Provincias. Es más, Urgoiti se equivocaba en algo muy importante. La capacidad de supervivencia del periódico de partido, en situación de penuria y carestía como la de esta coyuntura, podía ser más alta que la de cualquier otro. La explicación no es otra más que el partido y su poder. Mientras unos dependen del mercado y sus oscilaciones, los otros lo hacen del partido y sus resultados electorales. Y la posibilidad de vivir del mercado en esta coyuntura parece casi imposible. Como prueba, el costo del papel a mitad de 1916: en apenas dos años, el precio había pasado de 14 a 29 pesetas el papel necesario para editar 1000 ejemplares. Si tenemos en cuenta que el precio de 
venta directa se mantenía en los cinco céntimos y que la comisión que percibían los vendedores e intermediarios era de dos, los diarios tan sólo ingresaban por cada 1000 ejemplares 30 pesetas. Con esta cifra, tal y como manifestaban los diarios, resultaba imposible cubrir el conjunto de gastos de redactores, empleados, administrativos, ordenanzas, taquígrafos, mecanógrafos, fotógrafos, caricaturistas, corresponsales, grabadores, tipógrafos, linotipistas, estereotipia, máquinas, cierre, franqueo, conducción, reparto, etc. Todo ello sin contar las tintas, engrases, plomos, fluido de motores, contribución industrial y de utilidades, etc. ${ }^{10}$

Creemos, por tanto, que ante la difícil coyuntura que se avecina a partir de la guerra, tuvieron más opciones de seguir adelante los periódicos de partido que los de empresa. En el caso valenciano, al menos, así fue lo que pasó. El Diario de Valencia, en febrero de 1916, en un artículo titulado "La vida de la prensa. Situación imposible", concluía reconociendo que, "como nosotros no nos lucramos con la prensa, ni tenemos más interés que la defensa de nuestros ideales y el servir al público, seguiremos como hasta de ahora hasta que Dios quiera y nuestras fuerzas nos lo permitan". No obstante, el 29 de junio de ese mismo año, en el mismo artículo de portada donde se celebraba el día de la prensa católica, el director del Diario, J.L. Martín, volvía a insistir en la necesidad de que los católicos contribuyesen económicamente superar la situación. Para justificar el llamamiento ofrecía un dato revelador: el diario necesitaba 500 pesetas diarias para poder seguir saliendo ${ }^{11}$. Poco tiempo después volvía a insistir en que la vida del diario dependía de "la generosidad de los buenos católicos". En agosto había una primera respuesta: recibían la herencia de un sacerdote, aunque tenían que compartirla con España Cristiana y La Voz de Valencia, lo que generó una dura batalla entre estas publicaciones.

El incremento del precio del papel empezó a provocar las primeras consecuencias a partir de 1916. Entre otras razones porque no fue la única subida. En esta coyuntura se producirá un aumento del precio del gas que alimenta los hornos de la linotipia y de la energía eléctrica con que marcha la rotativa. Tan sólo faltaba la subida de salarios, lo que no tardará en suceder.

Tras la nueva subida que experimenta el papel el 31 de enero de 1916, El Mercantil daba la primera señal de ahogo al publicar un artículo en que planteaba la necesidad de incrementar el precio del periódico en dos céntimos, esto es, a un total de 7 como precio de venta directa, al menos este era su deseo ${ }^{12}$. A este aviso siguió el Diario de Valencia que, más allá de sus diferencias políticas con el diario republicano, coincidía plenamente en la necesidad de incrementar el precio. Por su parte, El Pueblo, antes que tocar el precio, prefirió reducir el tamaño de su página en 2' 5 centímetros, saliendo a partir del 1 de mayo de 1916 con el nuevo tamaño.

Había estallado la cuestión del papel (Aubert, 2005). Y desde un primer momento se plantea como un problema que va más allá de las particularidades políticas o filosóficas de un periódico, pues afectaba al conjunto de las empresas u organizaciones que producían la prensa en España. La dimensión del problema unirá a los representantes de la prensa diaria en una asamblea que se celebrará en Madrid, el 24 de 
julio de 1916. En esta ocasión, a diferencia de la reunión mantenida en el mes de noviembre anterior, se pasa de las declaraciones y muestras de apoyo a una serie de debates más prácticos... "Ahora se discuten en la Asamblea de la Prensa temas tan importantes como el del papel, el franqueo, los horarios, de trenes, etc. Pero dentro de pocos días los fabricantes de papel subirán otra vez los precios, y lo que es ya un negocio malo, será dentro de pocos días una verdadera ruina..." Porque no sólo había subido el papel. También habían seguido la misma tendencia las tintas, metales, carbón, gas, electricidad, etc. Ante este negro panorama, la única salida que gozó de un cierto consenso fue la planteada por el propietario de $A B C$ : pedir ayuda al Estado a través de un sistema de anticipo reintegrable, de tal forma que la Administración abonase a las empresas periodísticas el 75 por 100 de la diferencia entre el precio del papel en 1914 y el que tuviese en esos momentos.

La siguiente asamblea se celebró el 14 de mayo de 1917 en la sede de la Asociación de la Prensa de Madrid. Allí se escucharon las voces de alarma que al unísono daban todos; allí se pudo escuchar de boca de Miguel Moya, presidente de la asociación anfitriona, las gestiones realizadas con el Gobierno; y allí se plantearon las posibles alternativas, como reducir el tamaño de los diarios y, sobre todo, dejar de salir un día a la semana. Pero si el problema era compartido, la solución posible los seguía dividiendo. La conclusión, por tanto, no fue ninguna. Es decir, se acordó crear una comisión "para que abarque todos los extremos y estudie detenidamente el asunto, que es de tan vital interés para la Prensa"13.

El fracaso de una alternativa semejante estaba en la negativa de parte de la prensa madrileña, en concreto Heraldo, ABC, El Imparcial y El Liberal, que no aceptaban de ninguna manera suspender la salida en un día. Y es que, directamente ligado a la cuestión del papel, acaba de surgir con fuerza un viejo tema llamado descanso dominical. Por este motivo, en vista de la alternativa que se debate en la Asamblea de Madrid, el Sindicato de Tipógrafos dirige a la prensa una carta defendiendo que... "la medida más acertada es que los periódicos dejen de publicarse los domingos, pues además de resolver el conflicto del papel con el menor perjuicio, es muy justo, muy humano y muy cristiano, que se santifique este día y se cumpla la ley del Descanso dominical vigente" 14 .

La deriva, como se desprende, amplia el panel de afectados, metiendo en el problema a un colectivo especialmente temido por las empresas: a los tipógrafos. La solución mayoritariamente aceptada la aportó Torcuato Luca de Tena y consistía en dividir los periódicos en tres categorías según su dimensión. La mayor parte de la prensa diaria valenciana quedaba encuadrada en el primer caso, donde se situaban los diarios de cuatro páginas. El suministro, por tanto, quedaba teóricamente avalado. No así el precio. A mediados de octubre de 1917, la Central Papelera informaba de un nuevo aumento de los precios. La escalda era geométrica: los 100 kilos de papel prensa habían pasado de 30/40 pesetas -según su calidad- en agosto de 1914, a 123/130 en estos momentos. El incremento vuelve a disparar el tema de la posible subida del precio de venta a 10 cts. Pero sigue sin haber acuerdo y, en buena medida, por culpa de El Pueblo. En efecto, el precio de venta para un diario republicano que 
nació vendiéndose a la mitad que el resto, constituía un medio para conseguir llegar al mayor número posible de público, vale decir electores. Si se conseguía este objetivo, luego vendría todo lo demás, esto es, el cargo público y la posibilidad de ayudar a compensar así las pérdidas del periódico. De nuevo el partido se erigía en colchón del diario.

El fiasco de la subida hizo reaparecer una vez más la alternativa de suspender la edición un día a la semana. Pero ahora tampoco se consideró, ya que si la pérdida de cada periódico estaba en torno a las 100 pesetas diarias, esto es, 700 a la semana, el ahorro de un solo día no paliaba en absoluto el problema. Finalmente, la solución se siguió buscando en el Estado. El 29 de julio de 1918 se aprobaba la Ley del Anticipo Reintegrable, que recopilaba todas las disposiciones anteriores al tiempo que dejaba aparcado el espinoso tema del precio de venta. En cualquier caso esta medida constituyó una vía fundamental para garantizar la vida de la prensa, al tiempo que significó nuevas dependencias para las empresas, pues el anticipo en términos generales no se llegó a devolver (Fuentes y Fernández, 1997: 185) (Sánchez y Barrera, 1992: 202)

\section{Conclusiones tras la guerra: volver a ser competitivos}

El 3 de noviembre de 1918, toda la prensa valenciana recogía la noticia de la firma del armisticio y abría un halo de esperanza a la negra situación en la que no faltaba, por no faltar, hasta una epidemia de gripe que había provocado enormes estragos, entre otros, en el mundo del espectáculo. La dinámica anterior de reuniones y asambleas para evaluar la situación y proponer alternativas seguirá siendo la tónica. En los inicios de 1919, los representantes de toda la prensa diaria valenciana constataban la paradoja de que a mayor tirada mayores pérdidas. Esto es, el precio de los costos hacía inviable el negocio, lo que obligaba sin alternativa a doblar el precio de venta. En efecto, a fines de mayo de 1919, hasta El Pueblo acepta el aumento, aunque propone su aplicación para después de las elecciones provinciales previstas para el 6 de julio. Mas pasaron las votaciones y el diario de Azzati no acababa de decidirse. Ante la espera, Las Provincias anuncia a sus lectores la subida el día 30 de junio, con la vana esperanza de que le siguieran todos ${ }^{15}$. También se sumó El Mercantil el 1 de junio, dando a sus lectores la siguiente explicación:

"Seguimos pagando el papel como en 1914: el anticipo reintegrable es sólo para la diferencia de este precio al que tiene actualmente el papel. Y sobre el precio de 1914 pagamos cada resma a la Central Papelera lo que debe cobrar del Estado. Es decir, que anticipamos el dinero que más o menos tarde ha de cobrar; y si no lo anticipamos, porque no podemos, pagamos por el aplazamiento de las letras el $6 \%$ de interés, lo que unido a $12{ }^{\prime} 5 \%$ en concepto de derechos reales y el $1{ }^{\prime} 5 \%$ de aumento de las tarifas ferroviarias, y los aumentos del gas, del carbón, de los jornales, de las grasas y de cuanto necesitamos para el periódico. Sólo pueden resistir esta situación aquellos periódicos de grandes empresas que cuentan con un capital de resistencia muy respetable. Los que aún disfrutando de vida próspera no cuentan con ese capital, no pueden de ningún modo librarse de ese cúmulo de dificultades que agravan la vida del periódico a medida que pasa el tiempo". 
Ante esta medida, El Pueblo contestó con una nota en la que reconocía que su caso era especial ya que... "un núcleo de patricios abnegados han liquidado hasta ahora el déficit que abrumaba a EL PUEBLO, como a las demás publicaciones diarias de la ciudad" 16 . La nota no dejaba de ser curiosa al revelar tan abiertamente las fuentes de financiación. Incluso podríamos tildarla de insolidaria por las graves consecuencias que podía provocar en el resto de diarios. Es más, El Pueblo no lo negaba... "Sabemos que esta actitud ocasionará graves quebrantos a nuestros colegas. Ellos no deben estimar nuestra situación como un gesto de competencia industrial, pues somos los primeros en proclamar, que si nosotros no hemos aumentado el precio del periódico no es porque no nos lo aconsejen las pérdidas, sino porque en este hogar, donde jamás faltaron corazones, se halló un grupo de hombres que nos ayuda a llevar la carga. Desde luego creemos que la Prensa de Valencia se venderá desde hoy a cinco céntimos". Y, desde luego, el mismo día en que El Pueblo publicaba la ruptura del acuerdo, el resto de la prensa diaria volvía a su precio antiguo, no si antes lanzar duras críticas al propio Azzati por su inconsecuencia ${ }^{17}$.

Pero la coyuntura de 1919 hacía insostenible la situación. El dilema era, sin discusión, o subir el precio o cerrar el periódico. Así se planteó en la asamblea de propietarios de periódicos diarios que se celebrará en Madrid a fines de año. El 16 de diciembre, cerca de 40 representantes de otros tantos diarios, firmaban la siguiente propuesta:

"Sin perjuicio de otra solución que contribuya a fortalecer los ingresos de los periódicos para hacer frente a la constante gravación de sus gastos, tanto en las primeras materias, como en la maquinaria, jornales y sueldos, los periódicos representados en esta Asamblea piden al Gobierno que con el mismo tesón e igual urgencia con que gestiona la solución del conflicto del papel, dicte una disposición por la cual se impida vender los periódicos desde $1^{\circ}$ de mes entrantes a menos de 10 céntimos el ejemplar"18.

El objetivo era una intervención del Gobierno para que obligase, a partir del 1 de enero de 1920, a que toda la prensa en España tuviese el mismo precio. Lo que ellos no sabían o no podían conseguir, lo reclamaban al poder. La respuesta del Ejecutivo, que en estos momentos preside Allendesalazar, será unir la subida del precio con el restablecimiento de la ley del descanso dominical, que entraría en vigencia a partir del 25 de enero de 1920. Por lo que respecta al nuevo precio de venta, se fijó definitivamente mediante Real Decreto de 13 de junio de 1920 en un mínimo en 10 céntimos, siempre y cuando no sobrepasase la superficie de 13.000 centímetros, esto es, aproximadamente 6 páginas. De superar esta extensión, el precio pasaba obligatoriamente a 15 cts. Así fue, al menos, hasta septiembre de 1922, en que la bajada del precio del papel posibilitó modificar la anterior normativa y consolidar el precio de 10 cts. para toda clase de diarios, independientemente de su tamaño.

La regulación confirmaba el inicio de un nuevo ciclo para la prensa valenciana. A partir de entonces los diarios volvieron a superar las estrecheces de las cuatro páginas, pasando a las 6 y muy pronto a las 8 . También se recuperan secciones tradicionales del diario que habían sido víctimas del recorte, como el folletín. El Mercantil 
Valenciano se permitirá llenar el hueco del lunes publicando, a partir del 26 enero de 1920, el semanario titulado El Mercantil del Lunes. También Las Provincias adoptó una salida similar al publicar a fines de enero de 1920 La Provincia Valenciana. Toda una demostración de que el descanso dominical no era aceptado por todos. Sin embargo, todos estos suplementos, bien por la resistencia obrera, bien por dificultad que implicaba consolidar un nuevo título, no pasaron de ser breves experiencias.

Finalmente, renace la pugna por la renovación tecnológica, sobre todo en aquellos diarios que no aprovecharon la coyuntura favorable de la primera década del siglo. Así, Las Provincias incorporaba en abril de 1921 una rotativa capaz de tirar ejemplares de 8 páginas a una velocidad de 20.000 copias por hora. Le seguirá El Pueblo, que en abril de 1923 adquiría una nueva rotoplana de la casa Buhler, de la que se destacaba que suprime la estereotipia, tira sobre tipos móviles, utiliza un molde por página, las modificaciones son instantáneas, se pueden imprimir instantáneamente 2 , 4, 6 ú 8 planas y entregarlas encartadas y engomadas. La reforma concluirá con la instalación, en el mes de junio, de una "estación radiotelegráfica propia en su edificio. El resto de la prensa diaria esperará al crecimiento que se vivirá a lo largo de la década de los años veinte para acometer nuevos cambios.

En suma, si la Gran Guerra tuvo efectos importantes en el periodismo español, como fue el desarrollo del reporterismo con la inclusión de la imagen, también los tuvo muy negativos en la evolución del proceso de modernización desarrollado desde fines del siglo XIX. El caso valenciano nos confirma cómo se produjo un cambio de ciclo respecto del experimentado en la década anterior. Si el principio básico entre los noventa y principios del siglo XX había sido el de producir más en menos tiempo y con un producto mejor acabado, a partir de 1914 la máxima será resistir más con menos. El incremento de costos en la producción del diario y la pérdida consiguiente de ingresos, no sólo detuvo los procesos de renovación del utillaje de producción o el incremento de las estructuras productivas, también abrió un importante debate en torno a cómo salvaguardar la vida de la prensa cuando el mercado no lo permite. Un debate muy presente hoy en día que, entonces, se resolvió con la ayuda del Estado. ¿Sobrevivirá nuestra agónica prensa en el futuro también gracias a las ayudas públicas?

\section{Bibliografía}

ACTON, E. (2001): "La transición a la política de masas: el impacto de la I Guerra Mundial", en La transición a la política de masas. Valencia: PUV.

AUBERT, P. (1986): "La propagande étrangere en Espagne pendant la Premiere Guerre Mondiale", en AA.VV.: Españoles y franceses en la primera mitad del siglo XX. Madrid: CSIC, pp. 357-411.

--- (2005): "Crisis del papel y consecuencias de la industrialización de la prensa (1902-1931)", en Homenaje a François Botrel, Bordeaux: PILAR, pp. 73-95. 
--- (2007): "Del «No pasa nada», al «Todo va bien»: Consecuencias de la práctica de la censura en España (1914-1930)", El Argonauta Español, http://argonauta. revues.org/1227; consultado el 24/03/2013.

CABRERA, M. (1994): La industria, la prensa y la política. Nicolás Maria Urgoiti (1869-1951). Madrid: Alianza Editorial.

DESVOIS, J.M. (1977): La prensa en España (1900-1931). Madrid: Siglo XXI.

ESPINET, F. (1989): "El segundo frente informativo: revistas y prensa especializada", en Historia de los medios de comunicación de España. Periodismo, imagen y publicidad (1900-1990). Barcelona: Ariel Comunicación.

FUENTES, J.F. y FERNÁNDEZ SEBASTIÁN, F. (1997): Historia del periodismo español. Madrid: Síntesis.

GARCÍA DELGADO, J.J. y JIMÉNEZ, J.C. (2001): Un siglo de España. La economía. Madrid: Marcial Pons.

GOMEZ, J.Ll. (1989): "Existió en España prensa de masas? La prensa en torno a 1900", en Historia de los medios de comunicación de España. Periodismo, imagen y publicidad (1900-1990). Barcelona: Ariel Comunicación.

GUEREÑA, J.L. (1982): "Las estadísticas oficiales de la prensa (1867-1927)", en Metodología de la historia de la prensa española, Madrid: Siglo XXI editores.

LAGUNA, A. (1999): El Pueblo, historia de un diario republicano (1894-1939). Valencia: IAM.

MARTINEZ GALLEGO, F.A.: "El declive. La etapa de T. Peris Mora, 1917-1929", en Historia de Levante-EL Mercantil Valenciano, Valencia: Editorial Prensa Valenciana, S.A.

MONTERO, E. (1983): "Luis Araquistain y la propaganda aliada durante la Primera Guerra Mundial”, Estudios de Historia Social, núms. 24-25, enero-junio, pp. 245-266.

PAZ, M.A. y MONTERO, J. (1999): El cine informativo (1895-1945): Creando la realidad. Barcelona: Ariel comunicación.

RIUS, I. y LAGUNA, A. (1992): "El compromiso republicano. La etapa de F. Castell (1874-1917)", en: Historia de Levante-El Mercantil Valenciano. Valencia: Prensa Valenciana, S.A.

SANCHEZ ARANDA, J.J. y BARRERA DEL BARRIO, C. (1992): Historia del Periodismo Español, desde sus orígenes hasta 1975. Pamplona: EUNSA.

SANCHEZ YLLAN, J.C. (1999): Prensa y política en la España de la Restauración. Rafael Gasset y El Imparcial. Madrid: Biblioteca Nueva.

SEOANE, M.C. y SÁIZ, M.D. (1996): Historia del periodismo en España, vol. 3, El siglo XX: 1898-1936. Madrid: Alianza Editorial. 


\section{Notas}

1 El Mercantil Valenciano afirmaba gastar, en abril de 1915, 1086 pesetas y el Diario de Valencia 1.054. Vid Diario de Valencia, 26-V-1915.

2 "Será objeto de la censura previa, solamente aquello que haga referencia al orden público y a la cuestión internacional. En el primero de estos grupos se entenderá incluido lo que se refiere a cuestiones obreras, movimiento societario que puedan producir alarma. El gobierno se recomienda en general la prudencia y el patriotismo de los periodistas que no deben emprender campañas de oposición. Desde luego, esta situación será provisional y se prescindirá de ella cuanto antes. Los comentarios y opiniones sobre la guerra serán sometidos a la previa censura con lo cual deberán los periódicos mandar las pruebas de galerada. El gobierno respetará todas las opiniones, siempre que coincidan con la suyas y solo en caso de absoluta necesidad hará callar por cualquier medio a los que no opinen como él. Pero respetará la libertad de la Prensa". El Pueblo, 9-IV-1917.

3 "Advertimos a nuestros lectores que, en virtud de la previa censura, no se puede tratar en los periódicos de los siguientes asuntos: De la cuestión militar. De movimiento de tropas. De Juntas de Defensa. De manifiestos y proclamas societarias. De mítines y huelgas. De movimientos de buques de guerra. De torpedeo de barcos nacionales o extranjeros en aguas jurisdiccionales. De exportaciones. Tampoco están permitidos los comentarios sobre la guerra. Prohibido queda también publicar con tachaduras o en blanco los espacios correspondientes a los párrafos retirados por la censura". El Pueblo, 4-VII-1917. Sin embargo, pocos días después, una comisión de directores de periódicos visitaba al ministro de la Gobernación, no sólo para protestar contra estas medidas, sino para proponer también una fórmula... "que cause menos molestias a la prensa. No se ha llegado a un acuerdo, pero se ha convenido un nuevo régimen: que lo tachado puede ser sustituido por puntos suspensivos. Se hará el ensayo durante unos días y luego se resolverá en definitiva". La Voz de Valencia, 11-VII-1917

4 Por de pronto, el 19 de junio, el ministro de la Gobernación decide personalmente suspender $E l$ Clamor de Castellón y ordenar que fuese cerrada la imprenta; el 2 de julio, La Voz de Valencia era multada con 500 pesetas por incluir dos pequeños espacios con líneas tipográficas vueltas al revés, cosa que estaba prohibida.

5 Diario de Valencia, 23-V-1915.

6 España, 9-III-1916

7 España, 10-II-1916

8 Diario de Valencia, 20-X-1917.

$9 \quad$ El Pueblo, 31-XII-1917

${ }^{10}$ Diario de Valencia, 27-VII-1916

${ }^{11}$ El propio director se quejaba de que se tenía fe, pero ello no se traducía en un compromiso económico con el diario... "La noble y cristiana iniciativa de los seminarista de Sevilla ha cuajado por fin y hoy es el día señalado para la celebración de determinados actos encaminados a exaltar a la Buena Prensa... dos clases de actos se van a celebrar hoy: actos religiosos, consistentes en misas y comuniones, y actos profanos, entre los que se cuenta la colecta que se ha de hacer en los templos a beneficio de la Buena Prensa... Pero el de la colecta(...)es depresivo porque tiene el carácter de limosna y la Prensa católica no necesita limosnas, sino lectores : la protección que se debe dispensar a los periódicos consiste en difundirlos y en retribuirlos y el recolectar para darles unas pesetas por una vez no resuelve ningún problema... Millares de Cofradías viven en Valencia con vida espléndida y superabundante, y en toda la región valenciana, una de las más piadosas de España, apenas podemos vivir dos diarios católicos... La Prensa necesita dinero, mucho dinero. Ya he dicho otra vez que el DIARIO cada día que sale a la calle ha realizado un gasto de más de cien duros. !500 pesetas diarias !... Yo creo que mujeres como 
doña Leonor Ortiz, que regaló una rotativa para la Prensa Católica, han de tener en el Cielo tanta gloria como las que edifican un templo..." Diario de Valencia, 29-VI-1916.

12 La realidad, como el mismo periódico reconoce, hacía inviable esta opción, ya que no existía fracción de moneda que permitiese el pago de 7 céntimos. Vid. El Mercantil Valenciano, 26-III-1916. Tal y como señalan SEOANE, M. C. y SÁIZ, M.D.: Historia del periodismo en España. 3, El siglo XX: 1898-1936. Alianza Universidad, Madrid, 1996, p. 67, "Algún periodista arbitrista propuso que se creara la moneda de siete céntimos para salvar esa dificultad".

${ }^{13}$ La Voz de Valencia, 15-V-1917.

${ }^{14}$ La Voz de Valencia, 26-V-1917.

15 Y, en efecto, le siguieron casi todos, argumentando la subida de forma muy similar. La Voz Valenciana de 30-VI-1919 afirma no necesitar justificar la resolución, ya que... "desde hace mucho tiempo nos venían imponiendo las condiciones económicas de nuestro trabajo, encarecido enormemente por efecto de la guerra. Lejos de volver a la normalidad de 1914, sigue gravándose nuestro presupuesto de día en día, y para vivir decorosamente nos vemos en la precisión de pedir este sacrificio a nuestros lectores. Por consiguiente, nuestros precios de suscripción serán en adelante: en Valencia, un mes, 2'50 pesetas; tres meses, 7'50 ptas.; fuera de Valencia, tres meses, 18 ptas.; y número suelto, 10 céntimos."

${ }^{16}$ El Pueblo, 10-VII-1919

${ }_{17}$ "Sin duda creía en eso hacerse el dueño de la capital, porque esperaría que todos leerían sólo exclusivamente su periódico, e inventó la combinación de que la junta de su partido no le permitía subirlo; pero ¿le autorizaba para empeñar su palabra y luego no cumplirla? Eso señor Azzati, usted sabrá qué nombre recibe." La Voz Valenciana, 10-VII-1919.

${ }^{18}$ La Voz Valenciana, 17-XII-1919.

\section{El autor}

Antonio Laguna Platero es profesor titular de Periodismo y Decano de la Facultad de Periodismo de la Universidad de Castilla la Mancha. Sus líneas de investigación se han desarrollado, tanto en la Historia de la Comunicación como en la Comunicación Política. Entre sus últimas publicaciones: Las razones del éxito político. Por qué votan los ciudadanos (Península, 2010); El secuestro de la democracia. Corrupción y dominación política en la España contemporánea (Akal, 2011); "Vicente Blasco Ibáñez: The epitome of radical journalism", en Journal of Blasco Ibáñez Studies (2012); "Propagar la libertad, 1808-1814", en Revista Internacional de Historia de la Comunicación (2013) 